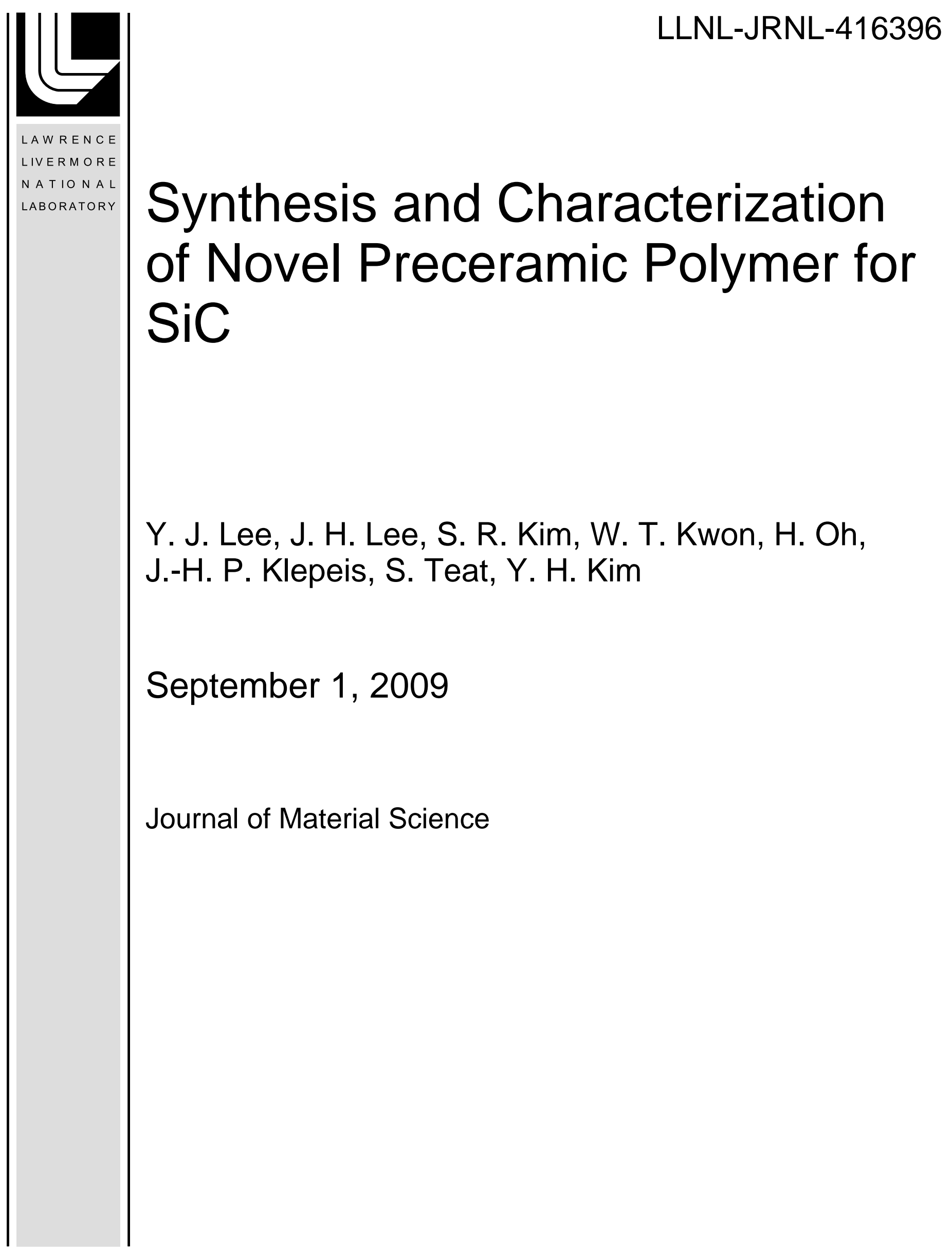


This document was prepared as an account of work sponsored by an agency of the United States government. Neither the United States government nor Lawrence Livermore National Security, LLC, nor any of their employees makes any warranty, expressed or implied, or assumes any legal liability or responsibility for the accuracy, completeness, or usefulness of any information, apparatus, product, or process disclosed, or represents that its use would not infringe privately owned rights. Reference herein to any specific commercial product, process, or service by trade name, trademark, manufacturer, or otherwise does not necessarily constitute or imply its endorsement, recommendation, or favoring by the United States government or Lawrence Livermore National Security, LLC. The views and opinions of authors expressed herein do not necessarily state or reflect those of the United States government or Lawrence Livermore National Security, LLC, and shall not be used for advertising or product endorsement purposes. 


\title{
Synthesis and Characterization of Novel Preceramic Polymer for SiC
}

\author{
Yoon Ju Lee ${ }^{\mathrm{a}}$, Jung Hyun Lee ${ }^{\mathrm{a}}$, Soo Ryong Kim ${ }^{\mathrm{a}}$, Woo Teck Kwon ${ }^{\mathrm{a}}$, Hyunju Oh${ }^{\mathrm{b}}$, \\ Jae-hyun Park Klepeis ${ }^{c}$, Simon J. Teat ${ }^{\mathrm{d}}$ and Y. H. Kim ${ }^{\mathrm{a} *}$ \\ ${ }^{a}$ Korea Institute of Ceramic Engineering and Technology, Seoul, Korea, 153-801 \\ ${ }^{\mathrm{b}}$ Institute of Basic Science, Sungshin Women's University, Seoul, Korea, 136-742 \\ ${ }^{\mathrm{c}}$ Lawrence Livermore National Laboratory, Livermore, CA 94550, USA \\ dAdvanced Light Source, Lawrence Berkeley National Laboratory, Berkeley, CA 94720, USA \\ *E-mail address:yhkokim@kicet.re.kr
}

\begin{abstract}
Polyphenylcarbosilane as a novel preceramic polymer for $\mathrm{SiC}$ was synthesized from thermal rearrangement of polymethylphenylsilane around $350^{\circ} \mathrm{C} \sim 430^{\circ} \mathrm{C}$. Characterization of synthesized polyphenylcarbosilane was performed with ${ }^{29} \mathrm{Si},{ }^{13} \mathrm{C},{ }^{1} \mathrm{H}$ NMR, FT-IR, TG, XRD, and GPC analysis. From FT-IR data, the band at $1035 \mathrm{~cm}^{-1}$ was very strong and assigned to $\mathrm{CH}_{2}$ bending vibration in $\mathrm{Si}-\mathrm{CH}_{2}-\mathrm{Si}$ group, indicating the formation of the polyphenylcarbosilane. The average of the molecular weight $\left(\mathrm{M}_{\mathrm{w}}\right)$ of the polyphenylcarbosilane synthesized was 2,500 and easily dissolves in an organic solvent. TGA data indicates that polyphenylcarbosilane is thermally stable up to $400^{\circ} \mathrm{C}$. However, the rapid weight loss occurs above $400^{\circ} \mathrm{C}$ due to the pyrolysis of polyphenylcarbosilane, and the diffraction peak of pyrolysis residue at $1200^{\circ} \mathrm{C}$ corresponds to the $\beta$-SiC ceramic. The ceramic yield calculated from TGA is approximately $65 \%$.
\end{abstract}

Keywords: Polyphenylcarbosilane, Preceramic polymer, Polymethylphenylsilane, $\beta$-SiC

\section{Introduction}


Recently, various types of carbide and nitride ceramics have been prepared from preceramic polymeric precursors[1-7]. The most important advantage of using polymeric precursor is the easiness of the preparation at low processing temperature. Since preceramic polymers having moderate molecular weight are easily soluble in organic solvents such as cyclohexane, THF, xylene, preceramic polymers also allow to coat on metal, ceramic or graphite surface easily using spining, dip, spray coating methods to improve their anticorrosion, antioxidation properties. After crosslinking and having thermal treatment, preceramic polymer turns into amorphous ceramic in the range of $600^{\circ} \mathrm{C} \sim 900^{\circ} \mathrm{C}$, and crystalline ceramic phase above $1200^{\circ} \mathrm{C}$. The ceramic microstructure derived and chemical composition is strongly dependent on the composition of the polymer precursors used. Polycarbosilane is the most typical polymeric precursor for $\mathrm{SiC}$ ceramic and has been widely used since the pioneering work done by Yajima et al. on $\mathrm{SiC}$ fiber [2].

In general, polycarbosilane is synthesized by thermal decomposition of polydimethylsilane under high pressure in an autoclave [1]. For the reaction, Si radical has to be formed in the initiation step of the reaction and preparation of polycarbosilane from polydimethylsilane is carried out by Kumada rearrangement [1]. Kumada rearrangement of polydimethylsilane to polycarbosilane has been mostly studied by thermal decomposition at high temperature. However, this method contains significant operational problems such as generating gaseous by-products including $\mathrm{CH}_{4}, \mathrm{Me}_{3} \mathrm{SiH}, \mathrm{SiH}_{4}$ etc. The gaseous byproducts create extremely high pressure, normally higher than 100 atmospheres inside autoclave, which renders the operation inconvenient and unsafe.

To overcome these problems of thermal decomposition process, Yajima et al. adopted catalytic process in which polycarbosilane was synthesized at normal pressure by adding small amount of polyborodimethylsiloxane to polydimethylsilane as a catalyst [2]. Kim et al. also attempted to synthesize polycarbosilane at low pressure using zeolites as a catalyst such as ZSM-5, Zeolite A, Zeolite Y[3]. Also, Hasegawa et al. developed heterogeneous catalysts for this reaction 
such as $\mathrm{AlCl}_{3}, \mathrm{MnCl}_{3}, \mathrm{CrCl}_{3}, \mathrm{VCl}_{3}, \mathrm{TiCl}_{3}$ and $\mathrm{GaCl}_{3}$ etc [4]. However, the disvantage of using the catalytic method for the preparation of polycarbosilane is difficultness of catalyst sepataion, specially in case of nano catalytic powder. Also, contamination of catalyst gives deleterious effects on preceramic polymer properties.

In our study, a new method of synthesizing the preceramic polymer for $\mathrm{SiC}$ at low pressure is proposed by thermal rearrangement of polymethylphenylsilane. (Fig. 1) The thermal decomposition of polymethylphenylsilane above $350^{\circ} \mathrm{C}$ generates liquid by-products such as phenylsilane, methylphenylsilane, diphenylsilane etc. Therefore, synthesis of polyphenylcarbosilane from polymethylphenylsilane using an autoclave attached condenser generates less than 10 atmospheric pressures. Therefore polyphenylcarbosilane can be synthesized in much milder condition compared to those of polycarbosilane. The prepared polyphenylcarbosilane and by-

products during the thermal conversion were characterized with ${ }^{29} \mathrm{Si},{ }^{13} \mathrm{C},{ }^{1} \mathrm{H}$ NMR, FT-IR, TG, $\mathrm{XRD}, \mathrm{GPC}$ and GC analysis to understand its properties and structure.

\section{Experimental Section}

\section{Preparation of Polymethylphenylsilane}

Polymethyphenylsilane was synthesized through the reaction of methylphenyldichlorosilane with sodium metal in toluene solvent at $110^{\circ} \mathrm{C} .40 \mathrm{~g}$ of metallic sodium was chopped into small pieces and transferred into a $100 \mathrm{ml}$ toluene under inert atmosphere. At $110^{\circ} \mathrm{C}$, after sodium was entirely dispersed into toluene solvent, $100 \mathrm{~g}$ of methylphenyldichlorosilane was dropwised and refluxed for $7 \mathrm{~h}$. After the reaction, the unreacted sodium metal was removed by adding methanol. To remove $\mathrm{NaCl}$ and lower molecular weight of polymethylphenylsilane, the solid product was washed thoroughly with deionized water and acetone. The final product of white precipitate was dried under vacuum.

\section{Preparation and Purification of Polyphenylcarbosilane}


For the preparation of polyphenylcarbosilane, $20 \mathrm{~g}$ of polymethylphenylsilane was loaded into a 300ml autoclave reaction vessel attached condenser. After purging the sample with nitrogen gas, the temperature increased to $350{ }^{\circ} \mathrm{C}$ and kept for $6 \mathrm{~h}$ to occur Kumada rearrangement. Temperature was raised to $430^{\circ} \mathrm{C}$, and kept for another $6 \mathrm{~h}$ to increase the molecular weight of the polyphenylcarbosilane. During the synthesis, pressure of the autoclave does not exceed 20 atmospheres.

After the reaction, yellow viscous solid was obtained. The product was dissolved in cyclohexane and filtered to remove insoluble products, and then cyclohexane was evaporated using a rotary evaporator. Yellow brown viscous product was still obtained. Purification was done by heating under vacuum at $250^{\circ} \mathrm{C}$ for $30 \mathrm{~min}$ to remove the low molecular weight products. (Fig. 2) Yellow brown solid was remained in the middle of the furnace, and clear liquid byproduct was collected at the both side of furnace.

\section{Characterization}

${ }^{29} \mathrm{Si},{ }^{13} \mathrm{C},{ }^{1} \mathrm{H}$ NMR spectra were obtained using Varian Unity Inova $200 \mathrm{MHz}$ spectrometer. FT-IR spectra were obtained using a FTS-175C spectrometer in the range of 4000 to $400 \mathrm{~cm}^{-1}$. Molecular weight distribution of polyphenylcarbosilane was determined by a Gel Permeation Chromatography (Agilent) with Styragel column using tetrahydrofuran as a solvent. Polystyrene standard was used for calibration. Thermal decomposition of the polyphenylcarbosilane up to 1200 ${ }^{\circ} \mathrm{C}$ was measured by STA-MS-Skimmer TGA (Thermal Gravimetric Analysis) instrument under nitrogen atmosphere. XRD analysis of the powder after pyrolysis was carried out using a KFX987228-SE MAC Science make X-ray diffractometer employing a $\mathrm{Cu}$ target $\left(\mathrm{K}_{\alpha}=1,54 \mathrm{~A}\right)$.

In order to characterize the byproduct, the crystal precipitate out of the low molecular weight product, which is a clear solution, was coated with paratone oil and mounted on to a cryo-loop pin. The data of the small size single crystals were collected with Bruker APEX II detector with 
synchrotron radiation at beamline 11.3.1 of Advanced Light Source at Lawrence Berkeley National Laboratory. All data were collected at 150(2) K by using the w scan mode and integrated by using SAINT V7.34. Absorption correction was done with SADABS. Structures were solved by a direct method and refined with SHELXS package.

\section{Results and Discussion}

West and coworkers have synthesized polymethylphenylsilane (known as polysilastyrene) from the copolymerization of dimethyldichlolosilane and phenylmethyldichlorosilane [8]. However, this polymer itself is not suitable as a $\mathrm{SiC}$ precursor, because it is unstable and while it decomposes at high temperature it generates gaseous by-products including $\mathrm{CH}_{4}, \mathrm{Me}_{3} \mathrm{SiH}, \mathrm{SiH}_{4}$ etc. The gaseous byproducts, especially silane gas, render the operation inconvenient and unsafe. To make SiC precursor, West et al. tried to crosslink this polymer by photolysis using ultraviolet radiation at 350nm [9], and Krishnan et al crosslinked the polymer by chemically using divinylbenzene [10]. Although ceramic yield is increased approximately $40 \%$ by crosslinking, the polymer that is finally obtained is an insoluble white powder.

Preceramic polymers soluble in organic solvent allow to coat on metal, ceramic or graphite surface. It can be easily used by a spinning, dip, spray coating methods at room temperature, and converts to amorphous ceramic by heat treatment to improve their anticorrosion, antioxidation properties. For the application of $\mathrm{SiC}$ coating on various substrates to improve anticorrosion, antioxidation properties, it is required soluble $\mathrm{SiC}$ precursor having high ceramic yield.

To produce soluble SiC precursor with high ceramic yield, we prepared polyphenylcarbosilane from polymethylphenylsilane by thermal rearrangement at $350^{\circ} \mathrm{C}$ and the temperature was raised to $430^{\circ} \mathrm{C}$ to increase molecular weight of the polyphenylcarbosilane. (fig. 1) Polymethylphenylsilane was prepared by dechlorination and polymerization of methylphenyldichlorosilane using a sodium metal.

Formation of polymethylphenylsilane was confirmed by FT-IR and ${ }^{29} \mathrm{Si}$ solid NMR. Fig. 3 
(a) shows the FT-IR spectrum of prepared polymethylphenylsilane. The band at around $2950 \mathrm{~cm}^{-1}$ and $3066 \mathrm{~cm}^{-1}$ are assigned to $\mathrm{C}-\mathrm{H}$ stretching vibration in methyl group and phenyl group, respectively. The adsorptions were seen at $1098 \mathrm{~cm}^{-1}$ and $1248 \mathrm{~cm}^{-1}$ represent Si-phenyl stretching in phenyl group and $\mathrm{Si}-\mathrm{CH}_{3}$ deformation, respectively. All other peaks are in agreement with those reported in the literature.

Fig. 4 shows ${ }^{29} \mathrm{Si}$ solid NMR of polymethylphenylsilane. Singlet peak appears at $-37 \mathrm{ppm}$ assigned to Si-Si suggesting all the Si species are identical environment.

We tried to synthesized polyphenylcarbosilane from polymethylsilane around $350^{\circ} \mathrm{C} \sim 430^{\circ} \mathrm{C}$, since Kumada rearrangement of silane to carbosilane is known to occur around $350^{\circ} \mathrm{C}$. After the reaction, yellow brown viscous product was obtained. Purification was done by heating under nitrogen atmosphere at $250^{\circ} \mathrm{C}$ for $30 \mathrm{~min}$ to remove low molecular weight product. (Fig. 2) Yellow brown solid, which is polyphenylcarbosilane, was remained in the middle of the furnace, and clear liquid, which is trimethylphenylsilane, as a byproduct was collected at the both side of furnace.

\section{Characterization of polyphenylcarbosilane}

The formation of the polyphenylcarbosilane from polymethylphenylsilane is confirmed by FTIR spectrum. As shown in Fig. 3 (b), FT-IR spectrum of the synthesized polyphenylcarbosilane exhibits vibration bands at around $1035 \mathrm{~cm}^{-1}$, which is very strong, is assigned to $\mathrm{CH}_{2}$ bending vibration in $\mathrm{Si}-\mathrm{CH}_{2}-\mathrm{Si}$ group, indicating the formation of the polyphenylcarbosilane. Except $\mathrm{Si}$ phenyl stretching $\left(1098 \mathrm{~cm}^{-1}\right)$ and $\mathrm{C}-\mathrm{C}$ stretching in phenyl $\left(1486 \mathrm{~cm}^{-1}\right)$, these results are in agreement with those of polycarbosilane reported in the literature [2]. The quantitative chemical analysis data is consistent with the formulation of $\mathrm{SiC}_{9.4} \mathrm{H}_{11.3}$ for the polyphenylcarbosilane. Number average of molecular weight $\left(\mathrm{M}_{\mathrm{w}}\right)$ of the polyphenylcarbosilane determined by GPC is 2,500 and is easily soluble up to $30 \mathrm{wt} \%$ in organic solvents such as cyclohexane, THF, xylene etc.

Fig. 5 shows the ${ }^{29} \mathrm{Si}$ MAS NMR spectrum of the as-synthesized polyphenylcarbosilane from 
polymethylphenylsilane. The ${ }^{29} \mathrm{Si}$ MAS NMR spectrum as synthesized sample shows three splitted peaks at around $0,-17,-38$ ppms. Generally, the peak at around $0 \mathrm{ppm}$ is assigned to $\mathrm{SiC}_{4}$. However, this peak is splitted as several peaks since neighboring $\mathrm{SiC}_{\mathrm{x}} \mathrm{Si}_{4-\mathrm{x}}$ species originated from residual $\mathrm{Si}-\mathrm{Si}$ bond in the structure. The peak at $-17 \mathrm{ppm}$ is assigned to $\mathrm{SiC}_{3} \mathrm{H}$ and also this peak is splitted as several peaks since residual $\mathrm{SiC}_{\mathrm{x}-1} \mathrm{HSi}_{4-\mathrm{x}}$ species in the structure. Fig. 5 also exhibits small peaks at around $-37 \mathrm{ppm}$ for residual Si-Si species.

Fig. 6 shows ${ }^{1} \mathrm{H}$ NMR spectra of the polylphenylcarbosilane. The peaks at $0.85,1.28$ and around 7.5ppm are assigned to $\mathrm{CH}_{3}, \mathrm{CH}_{2}$ and phenyl group, respectively. Figure 7 shows ${ }^{13} \mathrm{C}$ NMR spectra of the polyphenylcarbosilane. The peaks at 1.28, 29.96 and around $130 \mathrm{ppm}$ are assigned to $\mathrm{CH}_{3}, \mathrm{CH}_{2}$ and phenyl group, respectively. The ratio of $\mathrm{CH}_{3}, \mathrm{CH}_{2}$ and phenyl group can be calculated from the integral of the peaks from ${ }^{1} \mathrm{H}$ and ${ }^{13} \mathrm{C}$ NMR spectra data.

The TGA curve exhibits large amount of weight loss up to $700^{\circ} \mathrm{C}$. This means that the organic groups of the polyphenylcarbosilane are decomposed in this temperature range. (Fig. 9) The weight loss of the polyphenylcarbosilane occurs the rapid weight loss above $400^{\circ} \mathrm{C}$ due to pyrolysis of polyphenylcarbosilane to $\mathrm{SiC}$ ceramic. The ceramic yield calculated from TGA is about $71 \%$ in the air and $65 \%$ under $\mathrm{N}_{2}$ atmosphere.

In order to examine the pyrolysis residue after heat treatment, the pyrolysis residue was crushed into a powdered form, and analyzed with XRD. Fig. 10 shows the X-ray diffraction results of the sample after heat treatment at $1200^{\circ} \mathrm{C}$ for $1 \mathrm{~h}$ under $\mathrm{N}_{2}$ atmosphere. The diffraction peak around $35^{\circ}$, $60^{\circ}$, and $73^{\circ}$ corresponded to the $\beta$-SiC. All the diffraction peaks were quite broad, which indicated that the sample was in the early stage of crystallization at the heat treatment temperatures.

\section{Characterization of Trimethylphenylsilane}

Purification was done by heating under nitrogen atmosphere at $250^{\circ} \mathrm{C}$ for $30 \mathrm{~min}$ to remove low molecular weight product. (Fig. 2) Yellow brown solid which is polyphenylcarbosilane was 
remained in the middle of the furnace and clear liquid was collected as a byproduct at the both side of furnace. Both crystals from the big crystals grown from the solution and tiny ones on the wall of the vial have a same crystal structure. The structure refinement was carried out in space group P21/c with cell parameters $a=18.524(6) \AA, b=9.544(2) \AA$ and $c=18.346(2) \AA, \beta=107.80(1)$ o. The building unit is Si monomer with three phenyl rings and one methyl group. Its structure was reported in the literature [11].

As shown in Figure 3, FT-IR spectrum of the triphenylmethylsilane is in agreement with those of triphenylmethylsilane purchased chemical reagent. Number average of molecular weight $\left(\mathrm{M}_{\mathrm{w}}\right)$ of the triphenylmethylsilane determined by GC is 277 .

Fig. $6 \mathrm{~b}$ shows ${ }^{1} \mathrm{H}$ NMR spectra of the methyltriphenylsilane. The peaks at 0.80 and around 7.5ppm are assigned to $\mathrm{CH}_{3}$ and phenyl group, respectively. Fig. $7 \mathrm{~b}$ shows ${ }^{13} \mathrm{C}$ NMR spectra of the methyltriphenylsilane. The peaks at -2.86 and approximately $130 \mathrm{ppm}$ are assigned to $\mathrm{CH}_{3}$ and phenyl

group, respectively. From the integral of the peaks from ${ }^{1} \mathrm{H}$ and ${ }^{13} \mathrm{C}$ NMR spectra data, the ratio of $\mathrm{CH}_{3}$ and phenyl group can be calculated.

\section{Conclusion}

In conclusion, we report the synthesis and characterization of polyphenylcarbosilane that is a suitable precursor for SiC ceramic. Polyphenylcarbosilane can be synthesized in much milder condition compared to those of polycarbosilane due to its liquid type thermal by-products rather than volatile type. Purification was done by heating under vacuum at $250^{\circ} \mathrm{C}$ for $30 \mathrm{~min}$ to remove the low molecular weight products. Number average of molecular weight $\left(\mathrm{M}_{\mathrm{w}}\right)$ of the purified polyphenylcarbosilane is 2,500 , and is easily soluble in organic solvents. The diffraction peak of pyrolysis residue at $1200^{\circ} \mathrm{C}$ corresponds to the $\beta$-SiC ceramic. The ceramic yield calculated from TGA is about $65 \%$. The obtained polyphenylcarbosilane, providing a good solubility in organic solvent, is a suitable precursor for coating using a solution process. 


\section{Acknowledgements}

The authors would like to thank Dr. Duk-Young Han in Korea Basic Science Institute, Seoul Branch for his assistance in data collection of the samples using Solid NMR, 200B instrument. Dr Klepeis work was supported under the auspices of the US DOE by LLNL under Contract DE-AC5207NA27344. Dr. Simon Teat and Dr. Klepeis's work on the methyltriphenylsilane structure analysis was carried out at the Advanced Light Source, Lawrence Berkeley National Laboratory. The ALS is supported by the Director, Office of Science, Office of Basic Energy Sciences, of the U.S. Department of Energy under contract No. DE-AC02-05CH11231.

\section{References}

1. Birot M, Pillot JP, Dunogues J (1995) Comprehensive Chemistry of polycarbosilanes, Polysilazane, and Polycarbosilazanes as Precursors of Ceramics. Chem Rev 95: 1443-1447

2. Yajima S, Hasegawa Y, Okamura K, Matsuzawa T (1978) Development of high tensile strength silicon carbide fibre using an organosilicon polymer precursor. Nature: 273 525-527

3. Riu DH, Kim SJ, Shin DG, Kim HR, Kim YH (2004) SiC fiber derived from the polycarbosilane prepared from the catalytic process. J. Ceram. Soc. Jpn 105: [7] 559-563

4. Hasegawa Y, Kobori T, Fukuda K (1986) Organosilicon Polymer and Process for Production Thereof. U.S. Pat. No. 4,590,253

5. LY HQ, Taylor R, Day RJ, Heatley F (2001) Conversion of polycarbosilane (PCS) to SiC-based ceramic part I, Characterization of PCS and Curing product. J. Mater. Sci, 36: 4037-4043

6. Takayama T (1998) A Strutural Study of Substituted polysilanes in the solid state by ${ }^{29}$ Si NMR J. Molecular Structure 441: 101-117

7. Tang M, Yu Z, Yu Y, Zhang L, Chen L (2009) Preparation of silicon carbide fibers from the blend of solid and liquid polycarbosilanes J. Mater. Sci. 44: 1633-1640 
8. SADABS; Sheldrick, GM (2004). SADABS Universitt Gttingen, Germany.

9. SHELXS; Sheldrick, GM (2008). Acta Cryst. A64, 112-122

10. West R, David LD, Djurovich PI, Sterky KL, Srinivasan KSV, Yu H (1981) Phenylmethylpolysilanes: formable silane copolymers with potential semiconducting properties. J. Am. Chem. Soc 103: 7352-7354

11. West R, David LD, Djurovich PI, Yu H (1983) Polysilastyrene:phenylmethylsilanedimethylsilane copolymers as precursors to silicon carbide. Am. Ceram. Soc. Bull 62: 899-903

12. Krishnan V, Bindu R, Chandrasekhar V, Murthy VSR (2002) Single-step synthesis of chemically cross linked polysilastyrene and its conversion to $\beta$-silicon carbide. J. Am. Ceram. Soc 85:[2] 504-506

13. Goethe JW (2005) Methyltriphenylsilane. Acta Cryst. E61: 3030-3031 